\title{
PEMANFAATAN GOOGLE MEET, GOOGLE CLASSROOM, DAN ZOOM UNTUK MENDUKUNG KEGIATAN BELAJAR DARI RUMAH
}

\author{
Amalia Anjani Arifiyanti ${ }^{{ }^{*}}$, Muhammad Burhanuddin F. ${ }^{1}$, Sudewantoro N.M. ${ }^{1}$, \\ Ananda Lakunti A. ${ }^{1}$, M. Rizal Abdullah Rozi ${ }^{1}$ \\ ${ }^{1}$ Program Studi Sistem Informasi, Universitas Pembangunan Nasional "Veteran" Jawa Timur \\ email: "amalia_anjani.fik@upnjatim.ac.id
}

\begin{abstract}
The school from home program implemented by all educational institutions during the COVID 19 pandemic forced all parties to adapt. This school from home program requires information technology as the medium so that the teaching and learning process continues. One of the challenges that arise from this distance learning method is the ability to operate information technology, especially applications used to support the online learning process. One of the activities to answer this challenge is to conduct training that directly practices how to operate an online learning support application. This training program attended by parents and students in the Sukodono District, Sidoarjo Regency. This training is carried out online due to a social restriction policy at the time of the training. The evaluation results and feedback from the training participants stated an increase in understanding of the operation of the applications being taught; besides, the participants indicated that the community needed similar training. However, the participants hope that the next training will be carried out offline to teach the participants step-by-step directly.
\end{abstract}

Keywords: Google Meet; Google Classroom; school from home; training; Zoom

\begin{abstract}
Abstrak: Program belajar dari rumah yang dilaksanakan semua instansi pendidikan selama masa pandemi COVID 19, memaksa semua pihak yang terlibat untuk beradaptasi. Program belajar dari rumah ini membutuhkan teknologi informasi sebagai medianya agar proses belajar mengajar tetap berjalan. Salah satu tantangan yang muncul dari metode belajar jarak jauh ini adalah kemampuan pengoperasian teknologi informasi terutama aplikasi-aplikasi yang digunakan untuk mendukung proses belajar daring. Salah satu kegiatan untuk menjawab tantangan ini adalah dengan mengadakan pelatihan yang langsung mempraktekkan cara pengoperasian pengoperasian aplikasi pendukung belajar daring. Pelatihan ini diikuti oleh para orang tua dan siswa di wilayah Kecamatan Sukodono, Kabupaten Sidoarjo. Pelatihan ini dilaksanakan secara daring karena adanya kebijakan pem-batasan sosial pada saat pelatihan berlangsung. Hasil evaluasi dan timbal balik dari peserta pelatihan menyatakan bahwa terjadi peningkatan pemahaman terhadap pengoperasian aplikasi yang diajarkan, selain itu peserta menyatakna bahwa pelatihan sejenis dibutuhkan oleh masyarakat. Akan tetapi peserta berharap agar pelatihan selanjutnya dilaksanakan secara luring sehingga instruktur dapat mengajari peserta tahap demi tahap secara langsung.
\end{abstract}

Kata kunci: belajar dari rumah; google meet; Google Classroom; pelatihan; Zoom 
Available online at https://jurnal.stmikroyal.ac.id/index.php/jurdimas

\section{PENDAHULUAN}

Pandemi COVID-19 yang melanda seluruh dunia tidak terkecuali Indonesia mempengaruhi segala bentuk aktivitas masyarakat tidak terkecuali kegiatan belajar mengajar di sekolah. Kebijakan pemerintah untuk membatasi aktivitas sosial, memaksa seluruh jenjang pendidikan untuk beradaptasi dengan kondisi ini. Adaptasi yang dilakukan lembaga pendidikan adalah mengadakan program belajar dari rumah. Program ini dilaksanakan dengan berbagai metode mulai dari pemanfaatan media yang menggunakan internet (e-learning, aplikasi chatting, video-conference) hingga dukungan televisi nasional yang bekerja sama dengan Kementerian Pendidikan dan Kebudayaan (Kemendikbud) (MediaIndonesia, 2020).

Media belajar yang menggunakan internet seperti pemanfaatan e-learning dan video-conference dipilih instansi pendidikan untuk mendukung kegiatan belajar jarak jauh. Kondisi ini didukung juga dengan adanya beragam aplikasi e-learning dan video conference yang dapat diakses secara gratis maupun berbayar oleh para penggunanya. Google menyediakan layanan google classroom sebagai layanan e-learning tidak berbayar dan google meet sebagai dukungan terhadap layanan video-conference yang masih dapat diakses penuh secara gratis dengan ketentuan yang hingga saat ini terus mengalami perubahan sehingga pengguna sebaiknya terus mengecek laman ketentuan dari Google (Google, n.d.). Terdapat juga layanan video cloud zoom meeting atau dikenal secara singkat sebagai zoom yang menyediakan layanan video-conference secara berbayar namun dapat diakses secara gratis selama 40 menit awal setiap harinya.
Metode belajar jarak jauh ini mendukung siswa untuk belajar lebih mandiri dan siswa lebih berani mengemukakan opini dan idenya (Ismawati \& Prasetyo, 2020; Sadikin \& Hamidah, 2020). Di sisi lain, metode belajar ini mengalami tantangan pada ketersediaan sarana dan prasana untuk mendukung terlaksanakannya kegiatan belajar jarak jauh ini misalnya gawai untuk akses media belajar contohnya laptop/PC atau smartphone, hingga dukungan ekonomi untuk pembelian paket data internet (Hidayat, Anisti, Purwadhi, \& Wibawa, 2020). Untuk dukungan gawai dapat dipilih aplikasi yang dapat diakses melalui smartphone karena para siswa lebih banyak yang memiliki smartphone (Handarini \& Wulandari, 2020).

Tantangan lain dalam metode belajar jarak jauh adalah kemampuan penggunaan teknologi informasi (Salsabila, Sari, Lathif, Lestari, \& Ayuning, 2020) terutama bagi para pelajar yang masih duduk di bangku Sekolah Dasar. Dalam proses belajarnya, selain para guru yang memberikan instruksi secara daring, para siswa SD juga memerlukan bantuan orang tua sebagai instruktur langsung pada saat siswa melakukan proses belajar. Hal ini cukup menyulitkan jika orang tua tidak memahami materi belajar (al Fuad, 2020) atau bahkan orang tua tidak bisa meng-operasikan aplikasi sebagai media belajar daring. Hal inilah yang banyak terjadi di berbagai wilayah di Indonesia. Pengo-perasian media belajar yang umum digunakan pada saat belajar daring perlu dikenalkan kepada orang tua, sehingga orang tua dapat membantu para putra dan putrinya dalam proses belajar daring. 
Available online at https://jurnal.stmikroyal.ac.id/index.php/jurdimas

\section{METODE}

Pendekatan solusi dari permasalahan yang muncul karena diadakannya belajar dari rumah adalah mengadakan penyuluhan secara online bagi orang tua siswa dan siswa. Tahapan kegiatan penyuluhan mulai analisis kondisi, persiapan, hingga evaluasi kegiatan.

Analisis kondisi dilakukan pada tahap awal dengan tujuan untuk mengetahui kondisi lapangan dan kebutuhan dari calon peserta terhadap pembelajaran daring atau belajar dari rumah. Orang tua para siswa sekolah dasar di lingkungan Kecamatan Sukodono, Kabupaten Sidoarjo mengaku bahwa belajar dari rumah yang dialami putra-putrinya cukup mengalami kesulitan. Selain mengenai masalah ketersediaan sarana dan prasarana, masalah lainnya adalah kemampuan mengoperasikan platform daring yang digunakan oleh para siswa dan guru. Dikarenakan putra-putri para orang tua tersebut kebanyakan masih berada pada jenjang sekolah dasar, sehingga penggunaan platform daring ini perlu dukungan dari para orang tua siswa. Di sisi lain, para orang tua siswa juga memiliki kemampuan terbatas dalam mengoperasikan platform daring.

Beberapa sekolah melaksanakan metode belajar dari rumah menggunakan media chatting seperti Whatsapps untuk sharing tugas maupun juga pengumpulan tugas. Akan tetapi terdapat beberapa kesempatan digunakan platform videoconference untuk melaksanakan kegiatan belajar dari rumah. Untuk jenjang sekolah yang lebih tinggi, terdapat juga beberapa kasus yang platform pembelajarannya menggunakan e-learning dan dikombinasikan dengan media videoconference seperti Google Meet maupun Zoom.
Dari penjaringan opini dan observasi lapangan tersebut, maka diadakanlah pelatihan untuk pengoperasian platform belajar daring yaitu Google Classroom dan juga platform videoconference yaitu Google Meet dan Zoom yang saat ini lazim digunakan pada proses belajar dan mengajar.

Setelah tahap analisis kondisi dianggap cukup, tahap selanjutnya adalah melakukan persiapan kegiatan pelatihan. Persiapan ini terdiri dari dua kegiatan yaitu 1) Penjaringan calon peserta, dan 2) Penyusunan modul. Peserta pelatihan ini ditujukan untuk para orang tua di lingkungan Kecamatan Sukodono, Kabupaten Sidoarjo tetapi tidak menutup kesempatan bagi para siswa sekolah untuk mengikuti pelatihan ini. Putra-putri orang tua yang mengikuti pelatihan ini juga tidak terbatas sedang bersekolah di jenjang sekolah dasar. Bersamaan dengan kegiatan penjaringan calon peserta, dilaksanakan juga kegiatan penyusunan modul. Modul ini terdiri dari tiga bagian yang menjelaskan penggunaan 1) Google Classroom, 2) Google Meet, dan 3) Zoom.

Setelah tahapan persiapan selesai, maka tahap selanjutnya adalah pelaksanaan kegiatan. Kegiatan pelatihan ini dilaksanakan pada tanggal 30 Desember 2020 selama satu hari penuh, dan diikuti dengan Kegiatan pelatihan ini dilaksanakan secara daring menggunakan Google Meet. Pelatihan ini awalnya tidak dilaksanakan secara daring, namun bertepatan dengan tanggal pelatihan di wilayah yang menjadi lokasi pelatihan diadakan pembatasan sosial maka kegiatan ini dilaksanakan secara daring. Perubahan rencana ini mengakibatkan panitia menyediakan panduan siangkat untuk melakukan instalasi dan pengoperasian awal Google Meet yang menjadi platform pelatihan peserta. Peserta juga dapat 
menghubungi panitia agar dapat dibantu secara teknis dalam melakukan instalasi maupun menjalankan aplikasi ini untuk pertama kalinya.

Pada saat hari pelaksanaan dilaksanakan kegiatan pretest kepada peserta mengenai pemahaman peserta mengenai platform yang akan diajarkan pada pelatihan ini. Kegiatan berikutnya adalah pemaparan materi yang dilaksanakan oleh instruktur dan praktek yang diikuti oleh para peserta. Modul materi dikirimkan kepada masing-masing peserta sehingga diharapkan peserta dapat mengikuti materi yang disampaikan. Kegiatan pelatihan ini diakhiri dengan kegiatan post-test peserta.

Seluruh proses kegiatan pelatihan ditutup dengan kegiatan evaluasi kegiatan. Evaluasi ini dilaksanakan secara online dan dihadiri oleh seluruh anggota panitia pelaksana. Pada evaluasi ini dijabarkan mengenai hasil post-test dan timbal balik peserta mengenai kegiatan pelatihan ini. Di samping itu, juga disampaikan kritik dan saran mengenai teknis pelaksanaan pelatihan ini.

\section{PEMBAHASAN}

Pelatihan yang dilaksanakan di wilayah kecamatan Sukodono, kabupaten Sidoarjo pada tanggal 30 Desember 2020 diadakan sesuai dengan target peserta yaitu orang tua siswa meskipun tidak menutup kesempatan jika terdapat siswa yang ingin belajar mengenai media belajar secara daring. Proporsi peserta pelatihan dapat dilihat pada Gambar 2. Mayoritas peserta sebanyak $80 \%$ adalah orang tua siswa yang putra atau putrinya saat ini sedang duduk di bangku Sekolah Dasar hingga Sekolah Menengah Pertama (SMP), sedangkan sisanya yaitu sebesar 20\% adalah siswa yang saat ini menduduki jenjang SMP maupun SMA/K.

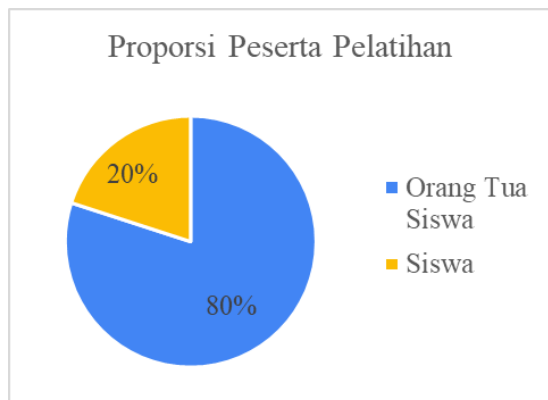

Gambar 1. Proporsi Peserta Pelatihan

Pada awal kegiatan, peserta mengikuti pretest mengenai pemahaman peserta mengenai penggunaan media belajar daring yaitu Google Meet, Google Classroom, dan Zoom. Hasil dari pretest peserta dapat dilihat pada Gambar 3. Tingkat pemahaman peserta dinilai dari rentang 1 hingga 5 dengan nilai 1 adalah sangat tidak paham hingga 5 yang berarti peserta sangat paham.

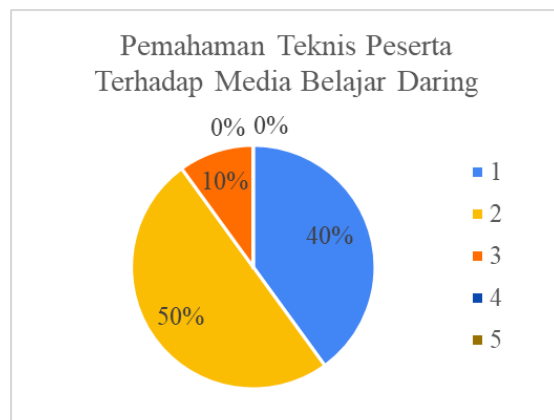

Gambar 2. Tingkat Pemahahaman Teknis Media Belajar Daring Sebelum Pelatihan

Pelaksanaan pelatihan cukup berhasil dilaksanakan dengan baik meskipun waktu pelaksanaan pelatihan mundur cukup banyak daripada yang direncanakan. Hal ini dikarenakan pada saat pelatihan akan dilaksanakan mayoritas peserta masih menghubungi panitia untuk meminta bantuan mengenai cara menjalankan aplikasi Google Meet meskipun 
Available online at https://jurnal.stmikroyal.ac.id/index.php/jurdimas

pada saat pendaftaran peserta, calon peserta telah diberikan panduan awal untuk menggunakan aplikasi video-conference ini. Selain itu, pada saat praktek pemateri harus memberikan instruksi yang lebih detail kepada peserta. Hal ini dikarenakan pelatihan yang diadakan secara daring, sehingga pemateri tidak dapat mendampingi peserta secara langsung (Gambar 4). Praktek secara daring ini cukup menyulitkan peserta karena beberapa peserta kurang memiliki kemampuan penggunaan teknologi informasi.

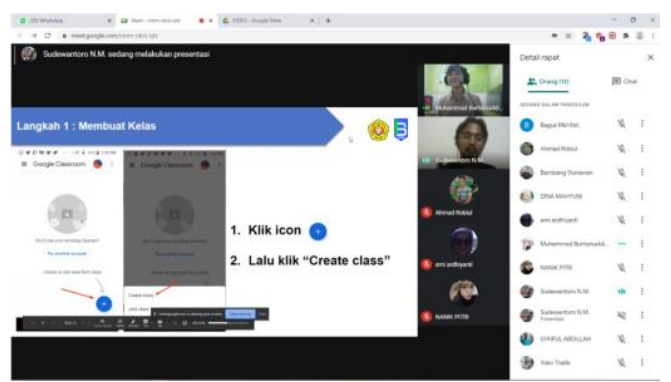

Gambar 3. Paparan Materi

Terdapat tantangan dari pelaksanaan pelatihan secara daring, hasil posttest peserta mengenai tingkat pemahaman teknis penggunaan media daring yang diajarkan pada pelatihan ini cukup mengalami peningkatan. Skala yang digunakan untuk menilai tingkat pemahaman peserta menggunakan skala likert. Skala yang digunakan pada post-test sama dengan skala yang digunakan pada pre-test. Berdasarkan hasil post-test, peserta minimal cukup paham (nilai 3) terhadap penggunaan media daring yaitu sebesar $40 \%$. Mayoritas peserta yakni sebesar 50\% mengaku paham (nilai 4) terhadap penggunaan media daring yang diajarkan. Meskipun jumlahnya sedikit, namun beberapa peserta menyatakan bahwa mereka sangat memahami (nilai 5) penggunaan teknis media daring yang diajarkan. Hasil perbandingan pre-test dan post-test dapat dilihat pada Gambar 5 .

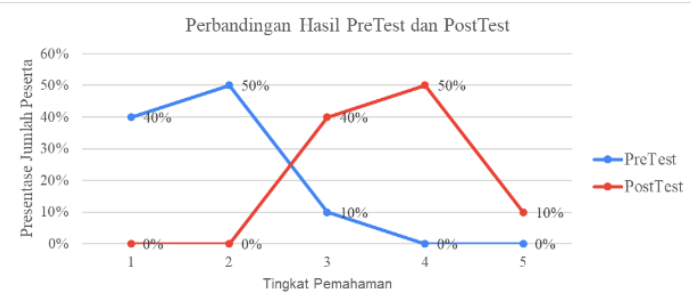

Gambar 4. Perbandingan Pemahaman Peserta Sebelum dan Sesudah Pelatihan

Hasil timbal balik dari peserta yang dihimpun pada akhir pelatihan menyatakan bahwa peserta terbantu dengan pelatihan ini dan berharap diadakan pelatihan sejenis, baik pelatihan untuk membantu kegiatan belajar putra putrinya, membantu meningkatkan efisiensi kegiatan sehari hari, hingga dapat membantu meningkatkan daya saing ekonomi masyarakat. Pengenalan penggunaan media berbasis teknologi informasi saat ini sangat dibutuhkan oleh masyarakat, namun sayangnya pelatihan mengenai pemanfaatan teknologi informasi ini dengan sasaran masyarakat umum tidak banyak dilakukan. Namun, peserta berharap pelatihan diadakan secara langsung atau luring. Hal ini dikarenakan mayoritas peserta tidak memiliki kemampuan dalam menggunakan media teknologi informasi secara umum.

\section{SIMPULAN}

Pelatihan yang ditujukan untuk membantu masyarakat terutama siswa maupun orang tua siswa yang mengalami kesulitan dalam menjalani program belajar dari rumah telah berjalan dengan lancar dan mampu membantu peserta dalam meningkatkan kemampuan penggunaan beberapa media belajar daring. Hal ini terlihat dari hasil evaluasi 
kegiatan yang menunjukkan pemahaman peserta di akhir pelatihan mengalami peningkatan yang cukup baik dibandingkan sebelum mengikuti pelatihan. Berdasarkan timbal balik dari peserta, peserta berharap diadakan pelatihan sejenis namun diadakan secara luring mengenai pemanfaatan teknologi informasi yang dapat mendukung tidak hanya kegiatan belajar saja, namun juga kegiatan seharihari masyarakat lainnya hingga peningkatan daya saing masyarakat secara ekonomi.

\section{DAFTAR PUSTAKA}

al Fuad, Z. (2020). Efektivitas Belajar Daring Siswa SD Banda AcehAceh Besar Pada Masa Pandemi COVID 19. PIONIR: JURNAL PENDIDIKAN, 9(2). https://doi.org/10.22373/pjp.v9i 2.8993

Google. (n.d.). Harga Google Meet. Retrieved March 13, 2021, from https://apps.google.com/intl/id/ meet/pricing/

Handarini, O. I., \& Wulandari, S. S. (2020). Pembelajaran Daring Sebagai Upaya Study From Home (SFH) Selama Pandemi Covid 19. Jurnal Pendidikan Administrasi Perkantoran (JPAP), 8(3), 2020. Retrieved from

https://journal.unesa.ac.id/index. php/jpap

Salsabila, U. H., Sari, L. I., Lathif, K. H., Lestari, A. P., \& Ayuning, A. (2020). Peran Teknologi Dalam
Pembelajaran Di Masa Pandemi Covid-19.Al-Mutharahah: Jurnal Penelitian Dan Kajian Sosial Keagamaan, 17(2), 188-198. https://doi.org/10.46781/almutharahah.v17i2.138

Hidayat, D., Anisti, Purwadhi, \& Wibawa, D. (2020). Crisis Management and Communication Experience in Education during the COVID-19 Pandemic in Indonesia. Jurnal Komunikasi: Malaysian Journal of Communication Jilid, $\quad 36(3), \quad 2020$. https://doi.org/10.17576/JKMJC -2020-3603-05

Ismawati, D., \& Prasetyo, I. (2020). Efektivitas Pembelajaran Menggunakan Video Zoom Cloud Meeting pada Anak Usia Dini Era Pandemi Covid-19. Jurnal Obsesi : Jurnal Pendidikan Anak Usia Dini, 5(1), 665. https://doi.org/10.31004/obsesi.v $5 \mathrm{i} 1.671$

MediaIndonesia. (2020, April 17). Program Belajar dari Rumah Bantu Peserta Didik hingga Orang Tua. Retrieved March 13, 2021, from https://mediaindonesia.com/hum aniora/304787/program-belajardari-rumah-bantu-peserta-didikhingga-orang-tua

Sadikin, A., \& Hamidah, A. (2020). Pembelajaran Daring di Tengah Wabah Covid-19. BIODIK, 6(2), 109-119.

https://doi.org/10.22437/bio.v6i 2.9759 